\title{
A method of treatment of multiple unilateral earlobe clefts
}

Geoffrey G Hallock MD

Division of Plastic Surgery, The Lehigh Valley Hospital, Allentown, Pennsylvania, USA

GG Hallock. A method of treatment of multiple unilateral earlobe clefts. Can J Plast Surg 1995;3(4):193-195. Multiple clefts of an earlobe are a unique problem that may well rise in incidence as a consequence of the changing tides of fashion, since currently adornment with multiple pierced earrings in both sexes has become prevalent. Depending on the location and number of clefts, immediate or sequential correction must preserve a maximum of tissue to prevent a diminutive or asymmetrical lobule. Although many alternatives used to repair the more common solitary cleft are quite acceptable, a variation of the 'tongue and groove' flap technique predictably recreates an earlobe with the desired normal appearance and contour.

Key Words: Bifid earlobe, Multiple cleft ear lobule

\section{Méthode de traitement des fissures unilatérales multiples au lobe de l'oreille}

RÉSUMÉ : Les fissures multiples d'un lobe de l'oreille constituent un problème unique, qui peut être une conséquence d'une mode passagère soit celle relativement récente des perçages d'oreilles multiples chez les deux sexes. Selon la localisation et le nombre de fissures, la correction immédiate ou séquentielle doit viser à préserver les tissus le plus possible afin de prévenir une diminution de la taille du lobe ou une asymétrie. Bien que de nombreuses solutions utilisées pour réparer les fissures solitaires courantes soient acceptables, une variation de la technique en $<<$ dents de scie $>>$ peut recréer de façon prévisible un lobe de l'oreille ayant l'apparence et le contour normaux.

Any method intended to correct the blemish of a congenital or acquired earlobe cleft must preserve symmetry in lobule dimensions and appearance. Deepithelialization followed by simple approximation of the edges of a solitary complete cleft as suggested by Boo-Chai may be expedient (1), but such longitudinal repairs commonly are followed by scar contracture and unacceptable notching at the free margin of the earlobe (Figure 1) (2). Local flap manipulations to create a staggered scar within the lobule such as a Zplasty (3) or variations of lap joints $(4,5)$ are intended to obviate this sequela. These manoeuvres can readily be adapted to repair multiple unilateral clefts, but no one, including Boo-Chai, has outlined any specific technical details for accomplishing this even though multiple tears are not an uncommon consequence of wearing several heavy pendant or hoop earrings (1). We present a modification of the tongue and groove flap 
principle similar to the L-plasty of Fearon and Cuadros (6) that has provided satisfactory results for immediate or staged repair of multiple tears of a single earlobe.

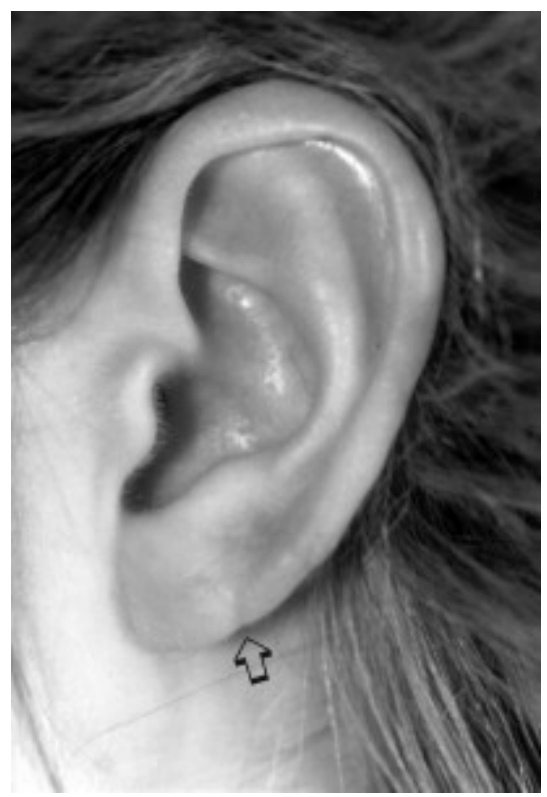

Figure I) Characteristic notch deformity at left earlobe margin (arrow) followed simple deepithelialization and direct approximation of opposing sides of a cleft. Barely seen above this are scars following a later staged repair of two additional clefts using 'tongue and groove' flaps

\section{METHOD}

When attempting to repair multiple clefts, as much of the earlobe as possible between clefts should be preserved if lobule dimensions are to remain unaltered. If this distance is minute, a staged approach should be considered, no matter how inconvenient for the patient, to maximize tissue preservation. Initially, only alternating clefts are closed under local anaesthesia using 'tongue and groove' flaps (Figure 2). Large, incomplete clefts are usually first converted to complete clefts (2) as part of the design of these flaps, or an unacceptable bulge at the lobule margin would result. The 'tongue' flap is always fashioned from the larger segment of earlobe adjacent to the cleft, otherwise the base could become too narrow and vascular embarrassment ensue. The 'groove' side margin is deepithelialized and notched to fit precisely the corresponding 'tongue', again with minimal tissue excision. Neovascularization across the resulting stair-step scar should be adequate within three weeks (7) to permit this sequence to be repeated ad infinitum until all clefts have been closed (Figure 3 ). 


\section{Hallock}

Multiple earlobe cleft repairs
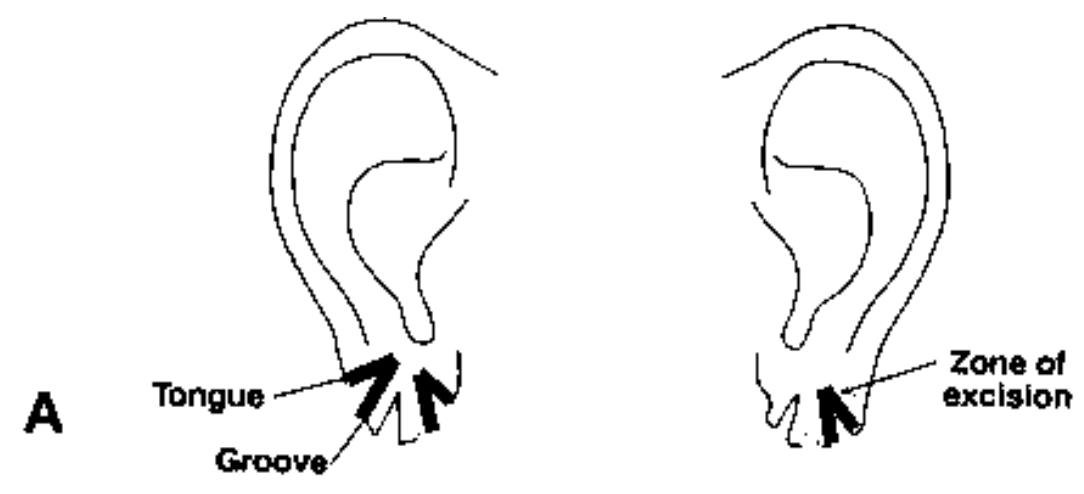

B
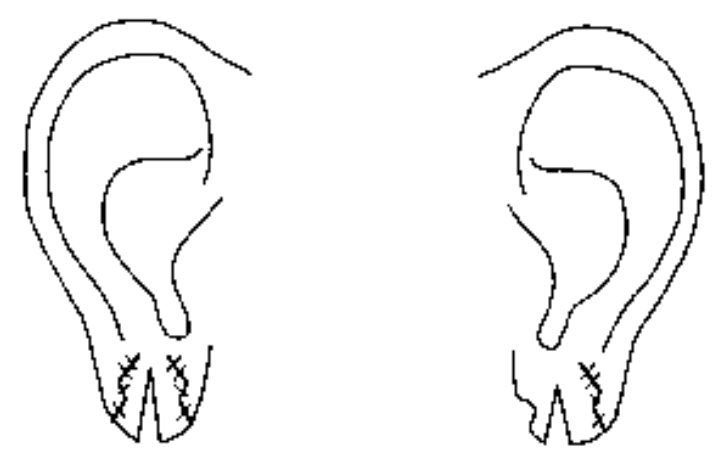

C
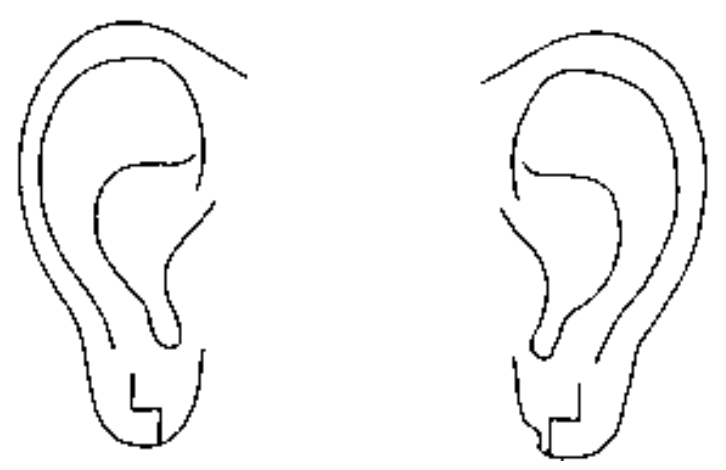

Figure 2) Schematic depicting proposed steps in the staged repair of a triple cleft earlobe (left) or double cleft (right). (A) Non-adjacent cleft margins are deepithelialized, and a series of 'tongue' flaps fashioned through and through from the larger side of the cleft(s). On the opposite side, a 'groove' is made to fit exactly the 'tongue' after its advancement. (B) This ultimately creates a more conventional solitary cleft; which, after an appropriate time for neovascularization across the scars, can similarly be converted via another 'tongue and groove' flap to a normal earlobe contour $(C)$ 

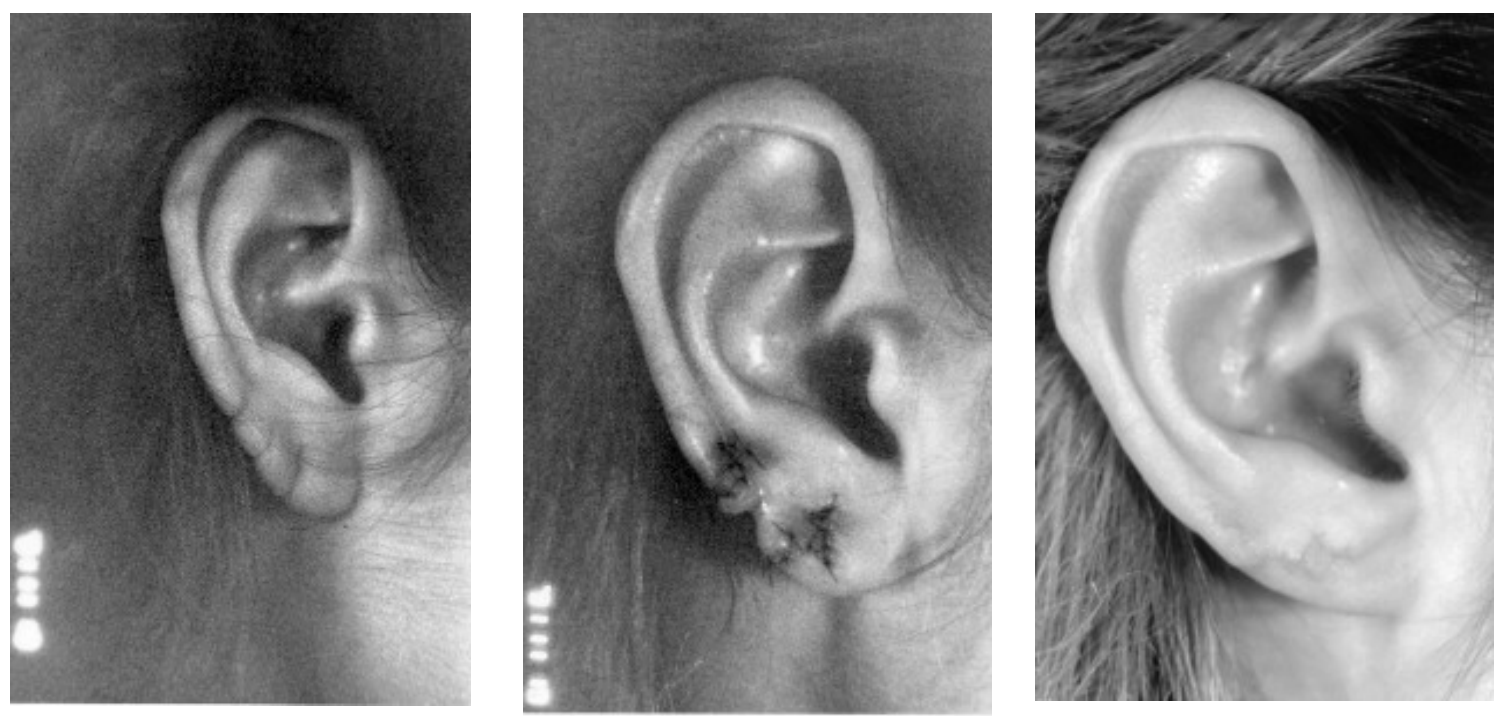

Figure 3) (Left) Triple cleft of right earlobe secondary to pierced earrings with two intervening small segments. (Middle) Completion of first stage using paired 'tongue and groove' flaps for elimination of the outside clefts only, resulting in a single residual cleft, (right) which was similarly closed three weeks later to leave a stair-step scar and smooth earlobe contour without notching

If the distance between clefts is relatively large, immediate repair of adjacent clefts may be more practical. Again, to ensure viability of the smaller earlobe segment between clefts, this fragment should by design be the recipient site for 'tongue' flaps made from opposing sides of different clefts (Figure 4). Unless extremely wide, this commonly requires reduction of its entire outer margin in height equal to that of the corresponding tongue flaps. The sum of the lengths of the 'tongue' flaps must be limited to the length of the residual arc of the intervening minor segment, as these all will be sewn together after advancement of the leading edges of the 'tonque' flaps toward each other to complete the repair. 


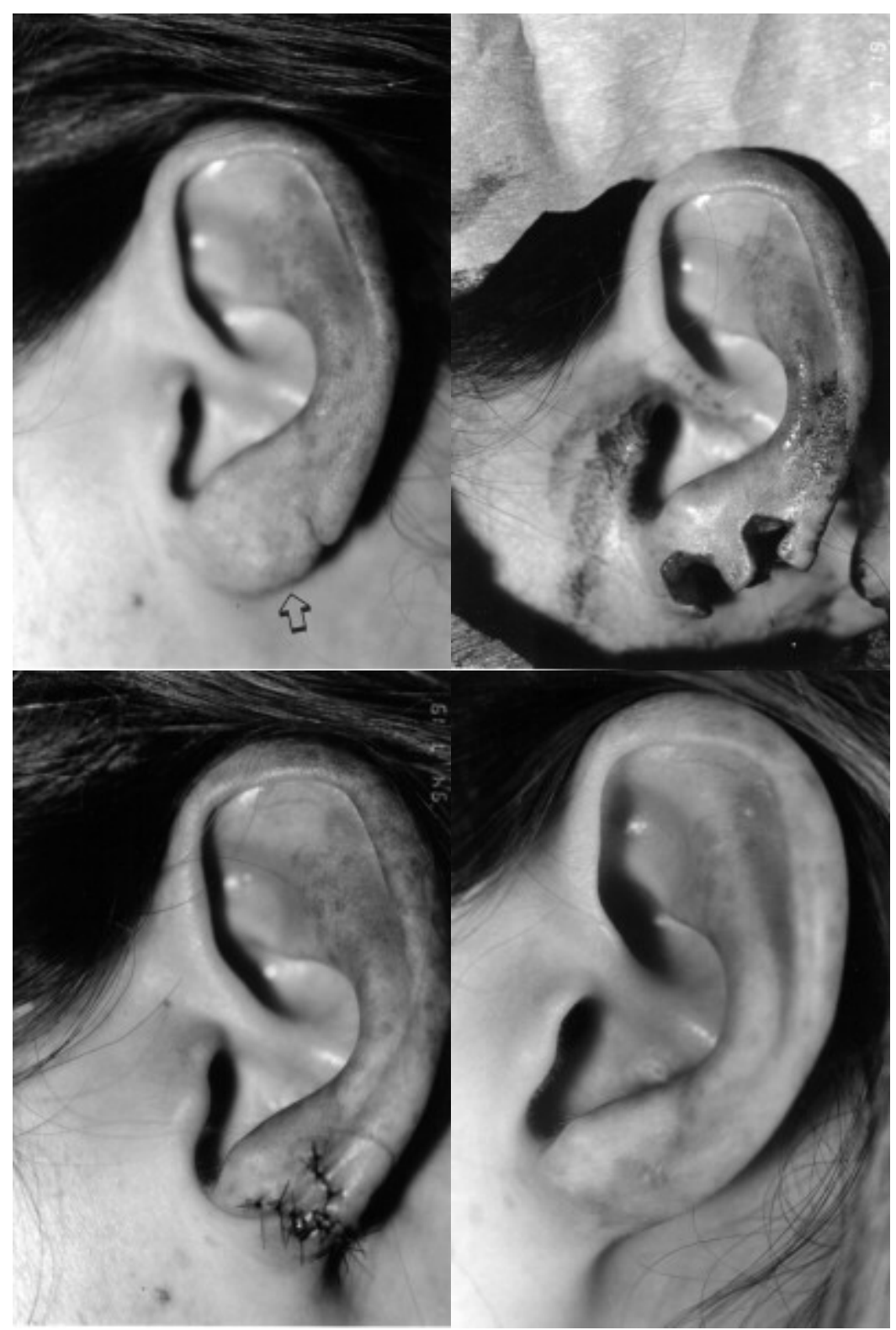

Figure 4) from left: Double cleft of left earlobe from pierced earrings. The more medial cleft slit is poorly seen (arrow); an immediate repair of both clefts was performed by creating 'tongue' flaps from the larger most medial and lateral portions of the earlobe, and reducing the height of the intervening earlobe segment by excising its free margin; the 'tongue' flaps were advanced to meet over the interposed minor segment, which has preserved a respectable earlobe size; allowing a final smooth contour of the lobule

\section{DISCUSSION}

Immediate repair of multiple unilateral earlobe clefts can be expediently achieved using any method acceptable for a solitary deformity (2), but this may result in discarding some portions or jeopardizing the circulation of small intervening segments. Our method of 'tongue and groove' flaps is such that parts initially from opposite sides of the cleft fused by the first scar can then serve as the next 'tongue' flap to repair the next adjacent 
cleft. Such a manoeuvre salvages as much tissue as possible (and perhaps supplemented by some scar mass) to prevent creation of a diminutive earlobe and preserve reasonable symmetry with the contralateral side.

Although the skin lining the apex of any given cleft can be retained (8) or a local margin flap fashioned to preserve an earring hole $(9,10)$, this is usually avoided in the treatment of multiple clefts as the ultimate location cannot be accurately predetermined. Instead, three to six weeks after the final stage, a new perforation may be created at the discretion of the patient.

This described 'tongue and groove' flap modification is a form of hinge (11) or rotation flap (12) ; and is almost identical to the L-plasty that we have used for over a decade for the solitary earlobe tear (6). Whether used for immediate or staged correction of multiple complete or incomplete earlobe clefts of a single auricle, the objective of a smooth contour of the lobule rim can be simply and effectively achieved.

ACKNOWLEDGEMENTS: Artwork courtesy of Carol Varma, Biomedical Photography, The Lehigh Valley Hospital, Allentown, Pennsylvania.

\section{REFERENCES}

1. Boo-Chai K. The cleft ear lobe. Plast Reconstr Surg 1961;28:681-8.

2. Bianco-Davila F, Vasconez HC. The cleft earlobe: a review of methods of treatment. Ann Plast Surg 1994;33:677-80.

3. Hamilton R, LaRossa D, Method for repair of cleft earlobes. Plast Reconstr Surg 1975;55:99-101.

4. Argamaso RV. The lap-joint principle in the repair of the cleft earlobe. Br J Plast Surg 1978;31:337-8.

5. Kalimuthu, R, Larson, BJ, Lewis, N. Earlobe repair: a new technique. Plast Reconstr Surg 1984;74:299-300.

6. Fearon, J, Cuadros CL. Cleft earlobe repair. Ann Plast Surg 1990;24:252-7.

7. Hallock GG. Skin recycling following neovascularization using the rat musculocutaneous flap model. Plast Reconstr Surg 1991;88:673-80.

8. Zoltie N. Split earlobes: a method of repair preserving the hole. Plast Reconstr Surg 1987;80:619-21.

9. Buchan NG. The cleft ear lobe: a method of repair with preservation of the earring canal. Br J Plast Surg 1975;28:296-8.

10. Pardue AM. Repair of torn earlobe with preservation of the perforation for an earring. Plast Reconstr Surg 1973;51:472-3.

11. Attalla MF. Congenital earlobe cleft: a new technique for repair. Br J Plast Surg 1990;43:223-5.

12. Effendi SH. Reconstruction of the middle-aged torn earlobe: a new method. Br J Plast Surg 1988;41:174-6. 